\title{
Great auricular nerve schwannoma in neck region: a case report with the risk of medical disputes
}

\author{
Chunling $X u^{1}$ and Qingjia Sun ${ }^{2^{*}}$
}

\begin{abstract}
Background: Great auricular nerve schwannoma is extremely rare. Herein, we reported the first case of schwannoma arising from great auricular nerve trunk.

Case presentation: A 29 year-old female complained of a slowly-growing superfacial neck mass for 6 months. MRI revealed a high possibility of schwannoma. Although the patient underwent successfully surgical removal of the tumor, ipsilateral numbness of both auricle and peripheral skin developed due to traction of the nerve. Immunohistochemistry staining confirmed the diagnosis of schwannoma. And the patient has been followed regularly.
\end{abstract}

Conclusion: For superficial cervical tumors, the cervical plexus cutaneous nerve should be considered if MRI and other imaging findings suggest neurogenic tumors.

Keywords: Schwannoma, Great auricular nerve, Medical disputes

\section{Background}

Schwannoma is a benign neurogenic tumor originated from Schwann cells within peripheral nerve sheath. The disease commonly occurs in the head and neck region with an incidence of $25-45 \%$ [1]. Schwannoma in the head and neck region mostly originate from the eighth cranial nerve (vestibulocochlear nerve) [2], and it was most common in parapharyngeal space for the neck region. Schwannoma may also occur on other sites including the face, scalp, parotid gland (facial nerves), oral cavity, pharynx, larynx, and trachea [3]. In this case report, we presented a schwannoma originated from the great auricular nerve in the neck region.

\section{Case presentation}

A 29 year-old female was referred to the department of otorhinolaryngology head and neck surgery of the China-Japan union hospital of Jilin University, with a complaint of a slowly-growing mass in the neck region.

\footnotetext{
* Correspondence: asd831008@163.com

${ }^{2}$ Department of Otorhinolaryngology Head and Neck Surgery, The

China-Japan Union Hospital of Jilin University, Xiantai Street 126, Changchun

130033, China

Full list of author information is available at the end of the article
}

The physical examination showed that the mass was located approximately $2 \mathrm{~cm}$ below the lower margin of left mandible and adjacent to the anterior margin of sternocleidomastoid muscle. The mass was tough and unfixed without pressing pain.

Magnetic resonance imaging (MRI) showed a subcutaneous nodule in left neck with intermediate signal at both T1 and T2. MRI revealed a well-defined round-like mass (diameter $\sim 1.5 \mathrm{~cm}$ ) located on the superficial surface of sternocleidomastoid muscle. The mass presented inhomogeneous intermediate signal at T2 similar with Antoni A as well as Antoni B area. All the information above suggested a high possibility of schwannoma (Fig. 1).

Based on the clinical examination and imaging information, a surgery was performed subsequently. Patient was informed about provisional diagnosis, treatment options and potential postoperative complications. And the written consent was obtained from the patient as well. The treatment plan was approved by the institutional review board and ethics committee of our hospital.

External resection was performed under local anesthesia through a small incision. During the operation, a round-like tumor was observed. The tumor was smooth, well-encapsulated and well-defined with 


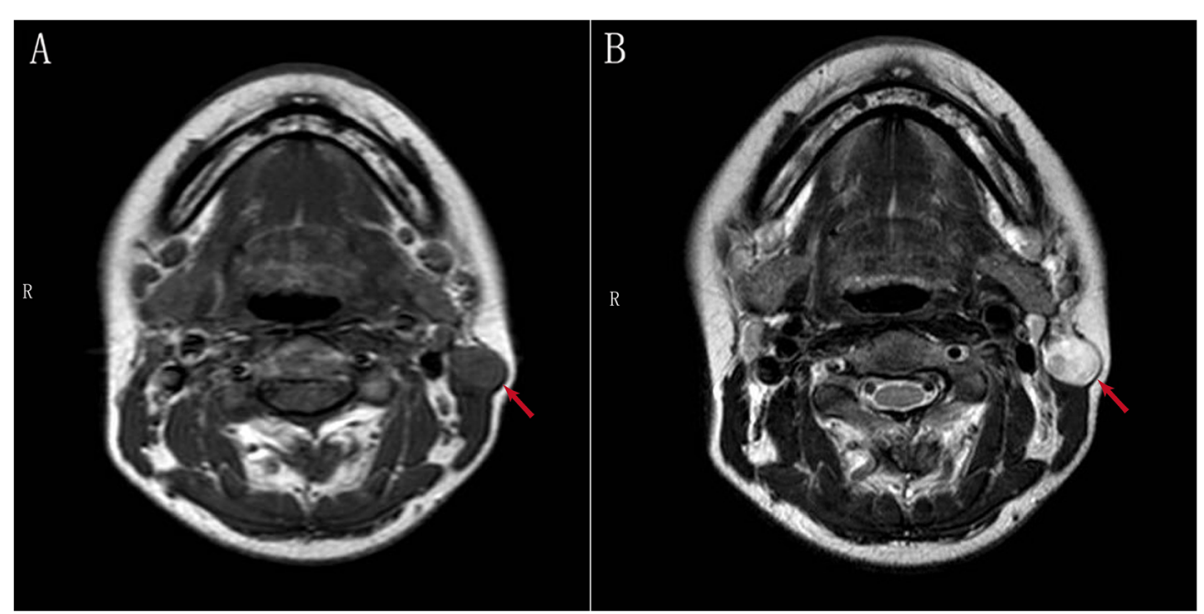

Fig. 1 MRI revealed a high possibility of schwannoma:a subcutaneous nodule in left neck with intermediate T1 (a) and T2 signal (b) as well as clear margin (red arrow). The mass presented inhomogeneous intermediate signal at T2 similar with Antoni A as well as Antoni B area (b)

surrounding tissues. The upper and lower poles of the mass adhered to the nerve (Fig. 2). The mass was removed by sharp dissection with the integrity of the capsule (Fig. 3). And the nerve was accompanied by external jugular vein.

Thereafter, the histopathological study described a benign cluster of spindle cells without mitosis, atypia or necrosis, but with some verocay bodies. The cells showed intense immunoreactivity for protein S-100. All characteristics were consistent with the diagnosis of schwannoma.

The patient developed immediate ipsilateral numbness of both auricle and peripheral skin due to traction of the nerve postoperatively. As to the superfacial mass of neck, we firstly took abnormal lymph node into account for that schwannoma originated from the trunk of the

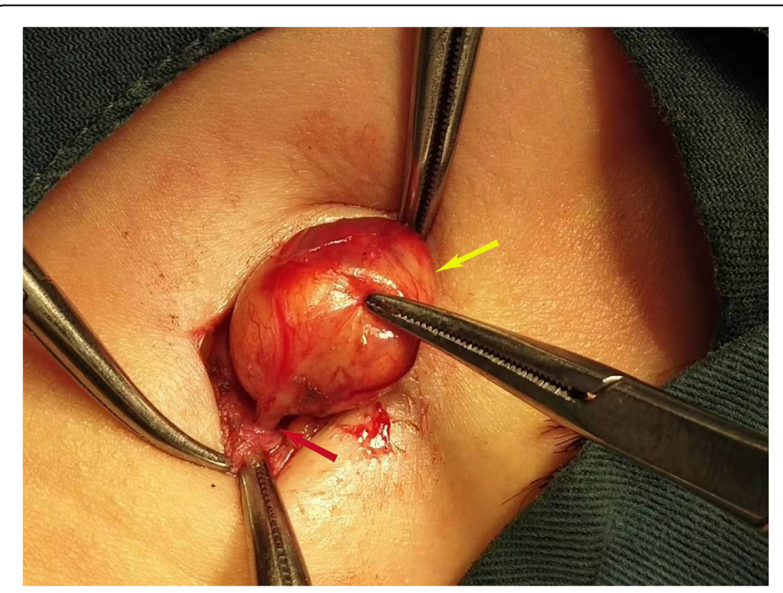

Fig. 2 Tumor connected with the nerve: the round-like tumor (yellow arrow) is smooth, well-encapsulated and well-defined with surrounding tissues, the upper and lower poles of which are seen to be connected with a nerve (red arrow) greater auricular nerve had not been reported previously. However, radiologists considered the possibility of schwannoma via MRI features. Therefore, we thought that the mass may originate from small sensory nerve fibers. Auricular numbness was not explained to the patient, nor was it reflected in the informed consent form before surgery. We explained to the patient about the causes of auricular numbness, and patient understood our explanation.

The local healing of the patient was good, and the suture was removed on the seventh day. Then the patient was followed-up regularly (every 3-6 months) [4].

\section{Discussion and conclusion}

Great auricular nerve schwannoma is extremely rare. According to the literature review, it was the first case of great auricular nerve schwannoma in neck region. Adhikary B et al. reported a solitary schwannoma in the postaural region [5]. Schwannoma was not reported originating from the trunk of the greater auricular nerve before, so we ignored the potential complication of auricle numbness. Although no disputes happened in this case, we immediately shared the case to otolaryngologists in countries with high possibility of medical disputes and violence such as China, Israel and India [6-8].

In this case, three diagnostic evidences confirmed that the tumor originated from the great auricular nerve: 1 ) within operation, the direction of the nerve coincides with the great auricular nerve. 2) after tumor resection, regional numbness of great auricular nerve innervation occurred. 3) characteristics of the mass meets with the diagnostic criteria for Enzinger and Weiss histologically.

In the case report, surgery was performed. To the best of our knowledge, surgery was more reported as the first choice for extracranial head and neck schwannomas, 


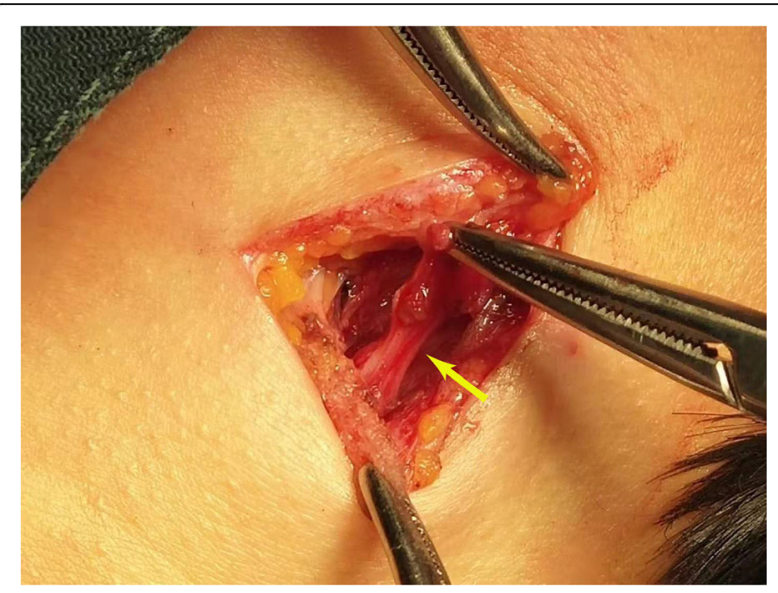

Fig. 3 The mass was removed by sharp dissection with the integrity of the capsule (yellow arrow)

possibly due to radio-resistance $[1,9,10] .$. Unlike malignancies, postoperative complications for benign, small and superficial tumors may be not acceptable by patients. For superficial cervical tumors, the cervical plexus cutaneous nerve should be considered if MRI or other imaging materials suggest neurogenic tumors. In this case, the trunk damage caused by removal of a mass, resulted in the regional numbness.

\section{Abbreviation}

MRI: Magnetic resonance imaging

\section{Acknowledgments}

This manuscript has been proofread by Medjaden Bioscience Limited.

\section{Authors' contributions}

QS developed the conception and design of the study, as well as the acquisition of data, analysis and interpretation of data as the corresponding author and gave final approval for this version to be published. CX contributed to the histological examination of lesions, and was a major contributor in writing the manuscript. The authors participated in the surgery carried out in this case and revised the manuscript critically for important intellectual content. All authors read and approved the final manuscript.

\section{Funding}

Not applicable.

\section{Availability of data and materials}

The datasets used and/or analysed during the current study available from the corresponding author on reasonable request.

\section{Ethics approval and consent to participate}

The case study and treatment plan was approved by the institutional review board and ethics committee of The China-Japan Union Hospital of Jilin University.

\section{Consent for publication}

Written informed consent was obtained for the patient according to federal and institutional.

guidelines. A copy of the consent form could be available for review by the Editor of this journal.

\section{Competing interests}

The authors declare that they have no competing interests.

\section{Author details}

'Department of Ophthalmology, The Second Hospital of Jilin University, Nanguan, Changchun, Jilin 130041, People's Republic of China. ${ }^{2}$ Department of Otorhinolaryngology Head and Neck Surgery, The China-Japan Union Hospital of Jilin University, Xiantai Street 126, Changchun 130033, China.

Received: 14 May 2019 Accepted: 15 November 2019

Published online: 01 December 2019

\section{References}

1. Tulli M, Bondi S, Bussi M. Voluminous laryngeal schwannoma excision with a mini-invasive external approach: a case report. Acta Otorhinolaryngol Ital. 2017;37(3):242-4.

2. Alrasheed W, Almomen A, Alkhatib A. A rare case of nasal septal schwannoma: case report and literature review. Int I Surg Case Rep. 2019; 55:149-51.

3. Kim YH, Lee JH, Park Y, Chung KJ. Schwannoma of the membranous nasal septum: a clinical report with aesthetic approach. J Craniofac Surg. 2018; 29(2):e120-2.

4. Soliman ZR, Mobashir MK, Askar SM. Trans-oral, carbon dioxide-assisted excision of an unusual schwannoma of the tongue base: case report and review of the literature. Int Arch Otorhinolaryngol. 2019;23(3):e354-9.

5. Adhikary B, Sen I, Basu AJ, Bandyopadhyay SN, Saha D, Basu SK. Solitary neurilemmoma in postaural region. J Indian Med Assoc. 2007;105(5):268277.

6. Leeat G, Merav BD, Gil BS, Shahar S, Samuel A: "Please do not act violently towards the staff": Expressions and causes of anger, violence, and aggression in Israeli cancer patients and their families from the perspective of oncologists. Transcultural Psychiatry. 2019;56(5):1011-1035.

7. Zhu L, Li L, Lang J, Magnavita N. Gender differences in workplace violence against physicians of obstetrics and gynecology in China: a questionnaire in the national congress. PLoS One. 2018;13(12):e0208693. https://doi.org/10. 1371/journal.pone.0208693. eCollection 2018.

8. Ghosh K. Violence against doctors: a wake-up call. Indian J Med Res. 2018; 148:130.

9. Nardi CE, Burzichelli AW, Pfuetzenreiter EG, Dedivitis RA. Schwannoma of the arythenoid. Einstein. 2013;11(2):224-6.

10. Hao Z, Changping C, Shili W, Huiru L, Yanfen Y, Xueming C. Extracranial head and neck schwannomas: a clinical analysis of 33 patients. Laryngoscope. 2010;117(2):278-81.

\section{Publisher's Note}

Springer Nature remains neutral with regard to jurisdictional claims in published maps and institutional affiliations.

\section{Ready to submit your research? Choose BMC and benefit from:}

- fast, convenient online submission

- thorough peer review by experienced researchers in your field

- rapid publication on acceptance

- support for research data, including large and complex data types

- gold Open Access which fosters wider collaboration and increased citations

- maximum visibility for your research: over $100 \mathrm{M}$ website views per year

At BMC, research is always in progress.

Learn more biomedcentral.com/submissions 